Fortschritt-Berichte VDl

VDI

Reihe 18

Mechanik/

Bruchmechanik

Nr. 355
M.Sc. Simeon Hubrich,

Hamburg

The hierarchical finite cell method for

nonlinear problems:

Moment fitting

quadratures, basis

function removel,

and remeshing 
https://doi.org/10.51202/9783186355188-1

Generiert durch IP '172.22.53.54', am 26.04.2023, 12:10:46.

Das Erstellen und Weitergeben von Kopien dieses PDFs ist nicht zulässig. 


\title{
The hierarchical finite cell method for nonlinear problems: Moment fitting quadratures, basis function removal, and remeshing
}

\author{
Vom Promotionsausschuss der \\ Technischen Universität Hamburg \\ zur Erlangung des akademischen Grades \\ Doktor-Ingenieur (Dr.-Ing.) \\ genehmigte Dissertation \\ von \\ Simeon Hubrich, M.Sc.
}

aus

Bremen

2021 


\section{Vorsitzender des Prüfungsausschusses}

Prof. Dr.-Ing. Thomas Rung

\section{Gutachter}

1. Gutachter: Prof. Dr.-Ing. habil. Alexander Düster

2. Gutachter: Prof. Dr. rer. nat. Ernst Rank

Tag der mündlichen Prüfung: 16. Februar 2021 


\section{Fortschritt-Berichte VDI}

Reihe 18

Mechanik/

M.Sc. Simeon Hubrich,

Bruchmechanik

Hamburg

Nr. 355

The hierarchical finite cell method for nonlinear problems:

Moment fitting quadratures, basis function removel, and remeshing

VDI verlag 
Hubrich, Simeon

The hierarchical finite cell method for nonlinear problems:

Moment fitting quadratures, basis function removel, and remeshing

Fortschr.-Ber. VDI Reihe 18 Nr. 355. Düsseldorf: VDI Verlag 2021.

176 Seiten, 111 Bilder, 7 Tabellen.

ISBN 978-3-18-335518-1, ISSN 0178-9457,

$€ 62,00 / \mathrm{VDI}-$ Mitgliederpreis $€ 55,80$.

Keywords: Finite cell method - Fictitious domain approach - High-order finite element methods - Numerical integration - Moment fitting quadratures - Basis function removal Remeshing - Data transfer - Nonlinear problems - Finite strain problems

In this thesis, several approaches are discussed in order to further enhance the performance of the finite cell method (FCM). Thereby, novel moment fitting quadrature schemes are introduced that allow to reduce the effort of the numerical integration process significantly. Further, a basis function removal scheme is proposed to improve the conditioning behavior of the resulting equation system. Finally, an innovative remeshing strategy is presented that overcomes the problem of severely distorted elements for simulations with large deformations.

\section{Bibliographische Information der Deutschen Bibliothek}

Die Deutsche Bibliothek verzeichnet diese Publikation in der Deutschen Nationalbibliographie; detaillierte bibliographische Daten sind im Internet unter www.dnb.de abrufbar.

\section{Bibliographic information published by the Deutsche Bibliothek}

(German National Library)

The Deutsche Bibliothek lists this publication in the Deutsche Nationalbibliographie

(German National Bibliography); detailed bibliographic data is available via Internet at www.dnb.de.

Arbeitsgruppe Numerische Strukturanalyse mit Anwendungen in der Schiffstechnik

(c) VDI Verlag GmbH · Düsseldorf 2021

Alle Rechte, auch das des auszugsweisen Nachdruckes, der auszugsweisen oder vollständigen Wiedergabe (Fotokopie, Mikrokopie), der Speicherung in Datenverarbeitungsanlagen, im Internet und das der Übersetzung, vorbehalten.

Als Manuskript gedruckt. Printed in Germany.

ISSN 0178-9457

ISBN 978-3-18-335518-1 


\section{Acknowledgements}

The present thesis is the result of my research work during my employment at the Institute for Ship Structural Design and Analysis (M-10) at Hamburg University of Technology (TUHH) in the period from January 2015 to April 2020. The work was funded by the Deutsche Forschungsgemeinschaft in the Priority Programme 1748 (DFG SPP 1748), in which the main objective was the development of modern non-standard discretization methods.

At this point, I would like to take the opportunity to thank everyone who contributed to my work and supported me during this time.

First of all, I would like to express my deep and sincere gratitude to my doctoral supervisor Prof. Dr.-Ing. habil. Alexander Düster. Dear Prof. Düster, many thanks for all the fruitful discussions, great suggestions, and your continuous support, which contributed considerably to the success of this work. While working with you, I was able to benefit a lot from your broad expertise and your long-time experience. Thank you very much!

Next, I would also like to thank Prof. Dr. rer. nat. Ernst Rank for acting as the second supervisor of my thesis - and Prof. Dr.-Ing. Thomas Rung for chairing my examination.

Further, I would like to thank all my colleagues at M-10 and of the SPP 1748 for the very successful and pleasant collaboration in many projects.

Furthermore, a big thank you goes to my family and friends for their support and for all the pleasant diversions from work.

Finally, I would like to express my deepest thanks to my love Anna. Dear Anna, over the years, we shared many happy adventures and have successfully overcome several challenges as a team. Together, we have a beautiful daughter. Thank you for your endless love, encouragement, and support during all these years. Thank you for everything, I love you so much! 
To my love Anna

and our beautiful daughter Clari,

I love you! 


\section{Contents}

1 Introduction 1

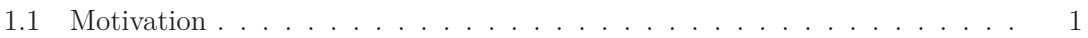

1.2 Goal and scope of this thesis . . . . . . . . . . . . . . . . . . . . . . . . . .

1.3 Outline of this thesis . . . . . . . . . . . . . . . 4

2 Basic elements of continuum mechanics 6

2.1 Kinematics . . . . . . . . . . . . . . . . . . . 6

2.1.1 Motion and deformation . . . . . . . . . . . . . 6

2.1 .2 Strain measures . . . . . . . . . . . . . . . . . . . 10

2.2 Equilibrium and stress measures . . . . . . . . . . . . . . . . . . . . 12

2.2.1 Equilibrium . . . . . . . . . . . . . . . . . . . . . . . . . . . . . . . . . . . . . . 12

2.2 .2 Stress measures . . . . . . . . . . . . . . . . . . . . . . . . . . . . . . . . . . . . . . . .

2.3 Constitutive equations . . . . . . . . . . . . . . . . . . . . . . . . . 15

2.3 .1 Linear elasticity . . . . . . . . . . . . . . . . . . . . . . . . . . . . . . . . . . 15

2.3.2 Hyperelasticity . . . . . . . . . . . . . . . . . . . . . . . . 15

2.3.3 Small strain elastoplasticity . . . . . . . . . . . . . . . . . . 16

2.3 .4 Finite strain plasticity . . . . . . . . . . . . . . . . . . . . . . . . . . . . . 17

2.4 Strong and weak form of equilibrium . . . . . . . . . . . . . . . . 18

2.4.1 Strong and weak form in the initial configuration . . . . . . . . . . 19

2.4.2 Strong and weak form in the current configuration . . . . . . . . . . 20

2.5 Linearization of the weak form . . . . . . . . . . . . . . . . . 20

2.5.1 Linearized weak form in the initial configuration . . . . . . . . . . 20

2.5.2 Linearized weak form in the current configuration . . . . . . . . . . 22

3 The finite cell method 23

3.1 Fictitious domain approach . . . . . . . . . . . . . . . . . . 23

3.1.1 Weak forms ........................ 24

3.1.2 Linearized weak forms . . . . . . . . . . . . . . . . . . 24

3.2 Spatial discretization . . . . . . . . . . . . . . . . . . . . . . . . . . . . . . . . . . . 25

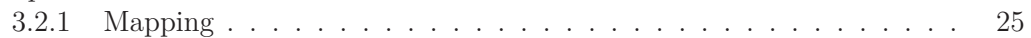

3.2 .2 Discretization of the weak forms . . . . . . . . . . . . . . . . . . . . . . . . . . 27

3.3 Numerical integration . . . . . . . . . . . . . . . . . . . . . . . . . . . . . . . . . . . . . .

3.3 .1 Gaussian quadrature . . . . . . . . . . . . . . . . . . 30

3.3.2 Adaptive Gaussian quadrature scheme . . . . . . . . . . . . . 33

4 Moment fitting quadratures $\quad 36$

4.1 Moment fitting approach . . . . . . . . . . . . . . . . . . . . . . 39

4.1 .1 Basis functions . . . . . . . . . . . . . . . . . . . . 40

4.1 .2 Point distribution schemes . . . . . . . . . . . . . . . . 41

4.1.3 Computation of the moments . . . . . . . . . . . . . . . 42 
4.1.4 Computation of the weights . . . . . . . . . . . . . . . 43

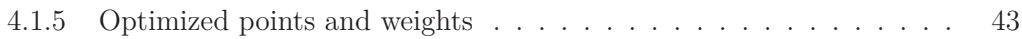

4.1 .6 Numerical examples . . . . . . . . . . . . . . . . . . . . . . . . . . . . . . . . . . 45

4.1.6.1 Cell cut by a sphere . . . . . . . . . . . . . . 45

4.1.6.2 Recovery of the Gauss-Legendre quadrature . . . . . . . . 54

4.2 Adaptive moment fitting . . . . . . . . . . . . . . . . . . . . 55

4.2.1 Moment fitting without solving an equation system . . . . . . . . . 57

4.2 .2 Computation of the moment fitting weights . . . . . . . . . . 59

4.3 Applications to the finite cell method . . . . . . . . . . . . . 60

4.3.1 Hydrostatic sphere . . . . . . . . . . . . . . . . . . . . . 6 . . . . . . . . . 60

4.3 .2 Porous material . . . . . . . . . . . . . . . . . . . . . . 66

4.3.2.1 Linear elasticity . . . . . . . . . . . . . . . 66

4.3.2.2 Small strain elastoplasticity . . . . . . . . . . . . . . . 69

4.3 .3 Cube with a cylindrical hole . . . . . . . . . . . . . . 72

4.3.4 Thick-walled plate with a circular hole . . . . . . . . . . . . 75

5 Basis function removal for the FCM $\quad 79$

5.1 A simple function removal strategy for the hierarchical basis . . . . . . . . 82

5.1.1 Affected and nonaffected modes of the hierarchical basis . . . . . . 83

5.1.2 Removal criterion of affected modes . . . . . . . . . . . . . . . . . . 84

5.1 .3 Implementation scheme . . . . . . . . . . . . . . . . . . . . . . . . . . . . . 85

5.2 Benchmark problem . . . . . . . . . . . . . . . . . . . 86

5.2 .1 Linear elasticity . . . . . . . . . . . . . . . . . . . . 88

5.2 .2 Small strain elastoplasticity . . . . . . . . . . . . . . . . . . . . . . . . . . . . . 92

5.3 Finite strain problems . . . . . . . . . . . . . . . . . . . . . . . 97

5.3.1 Single cube connector under pressure . . . . . . . . . . . . . . . . . . 98

5.3.2 Complex cube connector under pressure . . . . . . . . . . . . . 107

5.3.3 Single pore of a foam-like structure under pressure . . . . . . . . . . 116

6 A remeshing strategy for the FCM 124

6.1 Kinematic relations . . . . . . . . . . . . . . . . . . . . . . . . . . 124

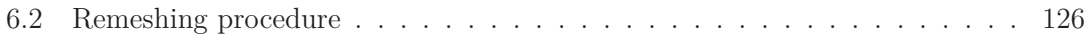

6.2.1 Remeshing criteria . . . . . . . . . . . . . . . . . 128

6.2.1.1 Ratio of Jacobians . . . . . . . . . . . . . . . . . . 129

6.2.1.2 Orthogonality . . . . . . . . . . . . . . . . 129

6.2.1.3 Inverse aspect ratio . . . . . . . . . . . . . . . . . 130

6.2.1.4 Performance of the suggested remeshing criteria . . . . . 130

6.2.2 Mesh generation . . . . . . . . . . . . . . . . . . . 132

6.2 .3 Data transfer . . . . . . . . . . . . . . . . . . . . . . . . . . . . . . . . . 134

6.3 Finite strain problems . . . . . . . . . . . . . . . . . . . . 137

6.3.1 Plate with a circular hole . . . . . . . . . . . . . . . . . 137

6.3.2 Single cube connector . . . . . . . . . . . . . . . . . . . . . 141

6.3.3 Complex cube connector . . . . . . . . . . . . . . . . 146

$\begin{array}{llr}7 & \text { Summary and outlook } & 150\end{array}$

$\begin{array}{ll}\text { Bibliography } & 154\end{array}$ 


\section{Abstract}

Over the last decade, nonstandard discretization methods based on the fictitious domain approach have gained increased interest. In these methods, the physical domain is embedded into a fictitious one - resulting in an extended domain of a simple shape. Consequently, structured meshes or Cartesian grids can be employed for the spatial discretization, thus simplifying the mesh generation process significantly. Due to this reason, such methods are a powerful tool for the numerical analysis of complex structures such as foam-like materials. A well-known example for these methods is the finite cell method (FCM), which combines the fictitious domain approach with high order finite elements. In the FCM, these elements are denoted as finite cells - thus giving the method its name - in order to distinguish them from boundary-conforming finite elements. However, the simplification in the mesh generation is accompanied by several numerical difficulties, induced by cut finite cells, reducing the efficiency and robustness of the FCM. In this thesis, we focus on the following issues in order to further improve the FCM.

The first topic is related to the numerical integration of finite cells. In general adaptive Gaussian quadrature schemes are used - commonly resulting in a large number of integration points, which renders the numerical integration computationally expensive. To overcome this problem, we propose novel quadrature methods based on moment fitting. Thereby, a promising approach is introduced that circumvents the necessity of having to solve an equation system. We show that this moment fitting method results in efficient and accurate quadrature rules for linear problems of the FCM, reducing the effort during the numerical integration process significantly. Moreover, in order to improve the performance for nonlinear applications, an adaptive moment fitting approach is presented.

The second topic addresses the ill-conditioning of the global system. To improve the conditioning behavior, we propose a new basis function removal approach applied to the hierarchic shape functions of the FCM. In this approach, shape functions with a small contribution to the diagonal entries of the global system matrix are removed from the ansatz. To this end, a global criterion based on the discrete gradient operator is introduced to estimate the contribution. Moreover, by maintaining the nodal modes of the hierarchic shape functions, the modified basis preserves the representation of the rigid body modes. Several examples show that the basis functions removal improves the conditioning behavior and, thus, the performance of the FCM significantly.

The last topic is related to the issue of severely distorted finite cells for applications in finite strain. To overcome this problem, we introduce a novel remeshing strategy that is based on a multiplicative decomposition of the deformation gradient. The essential idea of this strategy is to create a new mesh whenever the analysis fails due to severe distortions of the computational mesh - and then to continue the simulation. Further, a local radial basis function interpolation scheme for the implementation of the data transfer is presented. Considering problems of different complexity, we show that the remeshing strategy allows to improve the robustness behavior of the FCM considerably, especially in combination with the presented basis function removal. 